\title{
Profiling of eleusine coracana biscuits for glycemic index, stress and lipid
}

\author{
Abstract \\ Background: Eleusine coracana is one of the popular millet and has several health \\ benefits and some of which are attributed to its poly phenol and dietary fiber contents. \\ Regular intake of Eleusine coracana was known to reduce the risk of diabetes mellitus \\ and gastrointestinal tract disorders.
}

Objective: To investigate the glycemic index of Eleusine coracana biscuits and its consumption on lipid and stress levels in healthy subjects.

Design: Observational, prospective cohort.

Participants/setting: Participants were 12 healthy men human subject's age of 20$50 \mathrm{yrs}$ belongs to India.

Main outcome measurements: The association between frequency of Eleusine coracana biscuits consumption on lipid, stress levels and glycemic index was assessed. The Baseline of blood glucose levels were determined in all the subjects after overnight fasting for first three days.

Statistical analysis: Incremental area under curve of test food and reference food was calculated using trapezoidal rule and paired t-test was employed to find out the differences between before and after supplementation of EC biscuits in healthy subjects. Results were considered statistically significant when $\mathrm{p}<0.05$.

Results: The glycemic index of biscuits was found to be 33.95, which falls in low glycemic index range food. The glycemic load was found to be 16.97 the value which fit in moderate glycemic load food category. Supplementation of EC biscuits significantly increased $(\mathrm{p}<0.01) \mathrm{GSH}$ levels from $10.94 \pm 2 \mathrm{U} / \mathrm{L}$ to $11.85 \pm 2 \mathrm{U} / \mathrm{L}$ and MDA levels were gradually $(\mathrm{p}<0.05)$ decreased from $11.80 \pm 2 \mathrm{nmol} / \mathrm{ml}$ to $11.33 \pm 2 \mathrm{nmol} / \mathrm{ml}$ which might have resulted in significant improvement $(\mathrm{p}<0.001)$ in total antioxidant status from $11.6 \pm 3 \%$ inhibition to $14.59 \pm 4 \%$. A decrease $(\mathrm{p}<0.05)$ in LDL levels from $79.19 \pm 5 \mathrm{mg}$ / dl to $77.94 \pm 4 \mathrm{mg} / \mathrm{dl}$ was observed.

Conclusion: Eleusine coracana based biscuits have low glycemic index and moderate glycemic load which is suitable as a food supplement for diabetic population and others with life style diseases. The glycemic index values of foods are mainly dependent on the nature of cereal component. Long-term intake of Eleusine coracana biscuits may produce other health benefits including control of blood LDL levels and improving antioxidant status.
Volume I Issue 2 - 2017

TV Hymavathi,' Srinivasa K Rao, ${ }^{2}$ Pandu Boini, ${ }^{3}$ Rajesh P, ${ }^{3}$ Lily Rodrigues, ${ }^{4}$ Sunitha Sampathi, ${ }^{5}$ Venu Talla ${ }^{3}$

'Department of Foods and Nutrition, Agricultural University, India

${ }^{2}$ Indian Institute of Biotechnology Pvt Ltd, NIPER Hyderabad campus, India

${ }^{3}$ Department of Pharmacology and Toxicology, NIPER

Hyderabad, India

${ }^{4}$ General Physician and Diabetalogist, Surakshaka Diabetes and Multi specialty hospital, India

${ }^{5}$ Department of Pharmaceutics, NIPER Hyderabad, India

Correspondence: Venu Talla, Department of Pharmacology and Toxicology, NIPER Hyderabad, Balanagar, Hyderabad, 500037, India, Email venu@niperhyd.ac.in

Received: March 22, 2017| Published: July 07, 2017

\section{Introduction}

Diabetes mellitus is a disease caused by deficiency or lack effectiveness of endogenous insulin. It is characterized by hyperglycemia, deranged carbohydrate, and protein and lipid metabolism. ${ }^{1}$ Chronic hyperglycemia is associated with long-term damage, dysfunction, and failure of different organs, including mainly the eyes, kidneys, nerves, heart, and blood vessels. Chronic complications of diabetes are known to develop gradually. ${ }^{2}$ One of the clinical approaches for decreasing postprandial hyperglycemia is by preventing the absorption of carbohydrates after food uptake., Among the pharmacological and non-pharmacological approaches, management of diet is regarded as prevention as well as cure of Diabetes Mellitus. ${ }^{5}$

Concretely, the glycemic index (GI) of a food is a percentage value representing the area under the blood glucose response curve (over $2 \mathrm{~h}$ and measured at defined intervals) relative to the blood glucose response curve of a reference food (RF), originally may be glucose or white bread. ${ }^{6}$ The concept of glycemic load, the GI of a specific food multiplied by the amount of carbohydrate contained in an average portion of the food consumed, has been developed to represent both the quantity and the quality of the carbohydrate consumed. ${ }^{7}$ The best evidence of the clinical usefulness of GI is available in diabetic patients in whom low-GI foods have consistently shown beneficial effects on blood glucose control in both the short-term and the longterm. ${ }^{8,9}$ Several beneficial effects of low-GI, high-fiber diets have been shown, including lower postprandial glucose and insulin responses, an improved lipid profile, and, possibly, reduced insulin resistance ${ }^{10}$ Suggestive evidence is available from epidemiologic studies that a diet based on carbohydrate-rich foods with a low-GI, high-fiber content may protect against diabetes. ${ }^{11-16}$

Regular consumption of Eleusine coracana is known to reduce the risk of developing diabetes mellitus ${ }^{17}$ and its associated diseases, these properties were attributed to its high poly phenols and dietary 
fiber contents. ${ }^{18}$ Certain invitro \& invivo studies shown that Eleusine coracana has beneficial effects that may directly or indirectly protect against diabetes by Blood glucose lowering effect, ${ }^{19,20}$ decreases AGE (advanced glycation end product)formation, ${ }^{19}$ cholesterol lowering,,$^{19,20}$ antioxidant property, ${ }^{21,22}$ wound healing property, ${ }^{23,24}$ free radical scavenging, ${ }^{25}$ inhibition of collagen glycation and cross linking, ${ }^{26}$ aldose reductase enzyme inhibitory property, ${ }^{27}$ inhibition of intestinal $\alpha$-glucosidase and pancreatic amylase. ${ }^{1}$ As there were no studies on the health benefits of the biscuits prepared from Eleusine coracana, the present study was aimed at estimating glycemic index as well as effect on lipid and stress levels in healthy human subjects.

\section{Research design and methods}

$75 \mathrm{~g}$ of Eleusine coracana biscuits containing $50 \mathrm{~g}$ of carbohydrates were used as a test food which was developed in collaboration with Professor Jayashankar Telangana State Agricultural University (PJTSAU), Hyderabad and Glucose (Glucon-D $\left.{ }^{\circledR}\right)$ as a reference food.

\section{Study population and study approval}

Study population: 12 healthy male healthy human subjects age of 20-50 years old were included in the study. The inclusion criteria is; BMI (in $\mathrm{Kg} / \mathrm{m}^{2}$ ) "between" 20-25, non smoking, mentally unstressed, should engaged in moderate physical activity and not taking medication known to alter glucose tolerance.

Study approval: The study protocol was approved by Surakshaka Ethics Committee. Objectives and plan of the study was explained and written consent was obtained from all the subjects.

\section{Study design}

Twelve male healthy subjects took part in the study. Initially glucose tolerance test (GTT) was conducted to ensure the subject's glucose levels are normal. The results of the GTT were used initially for the selection of volunteers and later for the comparison with test product (Biscuits). Fifty grams of carbohydrates, which includes non-starch polysaccharides, of either glucose or Eleusine coracana biscuits were consumed by each subject, in random order on separate mornings after a $10-12 \mathrm{~h}$ overnight fast. For individual subjects, the tests were given 3 days apart. Biscuits were consumed over $10 \mathrm{~min}$ with tap water. Capillary finger-prick blood samples (3-4 drops) using Glucometer (ACCU-CHEK ${ }^{\circledR}$ ) was taken for subjects fasting (0min) and at 30,60, 90 and 120min after the start of the test meal. The subjects were supplemented with the biscuits for another 18 days and $2 \mathrm{ml}$ blood samples were collected for lipid and stress profile estimations. The blood samples were centrifuged and kept in $-80^{\circ} \mathrm{C}$ until analysis.

\section{Glycemic index (GI) method}

Glycemic index was calculated by dividing the incremental area under the curve of blood glucose concentrations measured after the ingestion of a portion of a test food containing $50 \mathrm{~g}$ carbohydrate by the incremental blood glucose area achieved with a portion of a reference food (RF) (glucose or white bread) containing the same amount $(50 \mathrm{~g})$ of carbohydrate and expressed as a percentage. ${ }^{28}$

GI of food was calculated by using following equation. ${ }^{29}$

$$
\mathrm{GI}=\frac{\text { IAUCoftestfood }}{\text { IAUCofreferencefood }} \times 100
$$

GL of food was calculated by using following equation. ${ }^{29}$

$$
\mathrm{GL}=\frac{\text { GIoftestfood }}{100} \times \text { availablecarbohydratesperservingsize }(\mathrm{gm})
$$

Each unit of dietary glycemic load represents the equivalent glycemic effect of $1 \mathrm{~g}$ carbohydrate from white bread/glucose, which was used as the RF. ${ }^{30}$

\section{Biochemical parameters}

Stress and lipid profiles in plasma were measured. Stress profile which include; lipid per oxidation by the method of Ohkawa et al $1979^{31}$ total reduced glutathione by Ellmann's modified method ${ }^{32}$ and catalase activity was determined by Aebi methods, ${ }^{33}$ by measuring the rate of decomposition of hydrogen peroxide at $240 \mathrm{~nm}$. The total superoxide dismutase (SOD) activity (cytosolic and mitochondrial) was determined using SOD assay kit (Sigma-Aldrich Co, St Louis, MO, USA) following manufacturer's specifications and total antioxidant status was determined by Despres et al. ${ }^{34}$ Lipid profile which includes plasma low density lipids (LDL), high density lipoprotein (HDL), triglycerides and cholesterol were estimated using respective Autozyme Enzyme kits (Accurex Biomedical Pvt. Ltd) by following manufacturer's specifications.

\section{Preparation of biscuits}

Ingredients were mixed in an electrical biscuit dough mixture and extruded through a biscuit dropping machine into desired shapes and baked in a rotary oven at $162^{\circ} \mathrm{C}$ for 30 minutes. The baked cookies were cooled on racks and then packed in polyethylene pouches until use for supplementation. The nutrient composition of Elusina corocona biscuits was given in Tables $1 \&$ Table 2. Each subject was supplied with $75.59 \mathrm{~g}$ of biscuits containing $50 \mathrm{~g}$ of available carbohydrates.

Table I Formulation of eleusine coracana biscuits

\begin{tabular}{ll}
\hline Ingredients & Percentage (\%) \\
\hline Ragi flour & 28.4 \\
Refined Wheat flour & 22.3 \\
Fat & 19.2 \\
Sugar & 24.3 \\
Skim Milk powder & 4 \\
baking powder & 1 \\
Ammonia & 0.8 \\
\hline
\end{tabular}

\section{Statistical analysis}

Graph Pad Prism, version 5.0 was used for the statistical analysis. All the results were expressed as mean \pm SD. Incremental area under curve (IAUC) of test food and reference food was calculated using trapezoidal rule. Paired t-test was employed to find out the differences 
between blood glucose levels before and after supplementation of Elusina corocona biscuits. Results were considered statistically significant when $\mathrm{p}<0.05$.

Table 2 Nutrient composition (\%) of biscuits

\begin{tabular}{ll}
\hline Nutrients & \% Composition \\
\hline Calories (K cal) & 452 \\
Protein $(\mathrm{g})$ & 5 \\
Fat $(\mathrm{g})$ & 19.8 \\
Carbohydrates $(\mathrm{g})$ & 66.5 \\
\hline
\end{tabular}

\section{Results}

\section{Blood glucose levels}

In twelve healthy human volunteers, one volunteer was discontinued in the middle of the study and the study was finished with eleven subjects. The mean baseline glucose was $92.69 \pm 15 \mathrm{mg} /$ dl. Baseline glucose levels were estimated for first three day's i.e. day1, day2, day3. The average baseline blood glucose levels of eleven subjects during these three days period were found to be $95.63 \pm 10 \mathrm{mg} /$ $\mathrm{dl}, 89.7 \pm 9 \mathrm{mg} / \mathrm{dl}$, and $92.78 \pm 13 \mathrm{mg} / \mathrm{dl}$ respectively in Table 3 .

Table 3 Baseline glucose levels

\begin{tabular}{lc}
\hline Baseline blood glucose levels $(\mathbf{m g} / \mathbf{d l})(\mathbf{n}=\mathbf{1 1})$ \\
\hline Day1 & $95.63 \pm 10$ \\
Day2 & $89.72 \pm 9$ \\
Day3 & $92.78 \pm 13$ \\
Avg & $92.69 \pm 15$ \\
\hline
\end{tabular}

All the subjects who were participated in the study were within the normal range $(80-120 \mathrm{mg} / \mathrm{dl})$. After administration of $50 \mathrm{~g}$ glucose, blood glucose levels were measured at different time points. The average blood glucose levels of GTT of the eleven subjects for a period of three days were shown in Table 4 . All the subjects who were participated in the study were within the range limits $(<200 \mathrm{mg} / \mathrm{dl})$.

After performing the GTT, three days washout period was given and the subjects were supplemented with test food (Eleusine coracana biscuits).Finally, blood glucose levels were measured at different time points as mentioned in Table 5.

The average and incremental blood glucose levels of reference and test food were shown in Table 6. For reference and test foods the average blood glucose levels were found between $92.95 \pm 16 \mathrm{mg} /$ $\mathrm{dl}$ to $148.58 \pm 39 \mathrm{mg} / \mathrm{dl}$ and $91.66 \pm 16 \mathrm{mg} / \mathrm{dl}$ to $108.64 \pm 27 \mathrm{mg} / \mathrm{dl}$ respectively. For reference and test foods the incremental blood glucose levels were found between 0 to $55.64 \mathrm{mg} / \mathrm{dl}$ and 0 to $16.98 \mathrm{mg} /$ dl respectively. Incremental blood glucose levels at different time points were calculated by subtracting baseline blood glucose levels $(92.95 \pm 16 \mathrm{mg} / \mathrm{dl}, 91.66 \pm 16 \mathrm{mg} / \mathrm{dl})$ respective time points of reference and test food.

The incremental area under curves (IAUC) for reference and test food was calculated using trapezoidal rule of area under the curve. The IAUC values of reference and test food were found to be $3711 \mathrm{mg}$. $\mathrm{min} / \mathrm{dl}$, 1100mg.min/dl respectively in Figures $1 \&$ Figure 2. The glycemic index and glycemic load of test food was found to be 33.95 and 16.97 respectively.

Figure 3 represents the comparison of incremental blood glucose levels of reference food which was found to be upto $150 \mathrm{mg} / \mathrm{dl}$ where as incremental blood glucose levels of test food was found within the normal range, that is lessthan $110 \mathrm{mg} / \mathrm{dl}$.

\section{Biochemical parameters}

The Lipid profiles of all the subjects were within in the normal range which was shown in Table 7. The base line levels of HDL, LDL, cholesterol, triglycerides were found to be $57.14 \pm 12 \mathrm{mg} / \mathrm{dl}$, $79.19 \pm 5 \mathrm{mg} / \mathrm{dl}, 115.97 \pm 32 \mathrm{mg} / \mathrm{dl}$, and $122.96 \pm 16 \mathrm{mg} / \mathrm{dl}$ respectively. After supplementation with biscuits the mean levels of HDL, LDL, cholesterol, tri glycerides levels were found to be $58.47 \pm 12 \mathrm{mg} / \mathrm{dl}$, $77.94 \pm 4 \mathrm{mg} / \mathrm{dl}, 103.31 \pm 3 \mathrm{mg} / \mathrm{dl}$, and $119.22 \pm 14 \mathrm{mg} / \mathrm{dl}$ respectively. The plasma LDL levels were significantly changed after supplementation with Elusina corocona biscuits $(\mathrm{p}<0.05)$. No significant changes were observed in HDL, triglycerides, and cholesterol levels after supplementation with biscuits Table 7 .

Before supplementation the mean levels of MDA, GSH, Catalase, SOD and DPPH were found to be $11.80 \pm 2 \mathrm{nmol} / \mathrm{ml}$, $10.94 \pm 2 \mathrm{U} / \mathrm{L}, \quad 112.95 \pm 45 \mathrm{U} / \mathrm{L}, 78.76 \pm 11 \mathrm{U} / \mathrm{ml}$, and $11.66 \pm 3 \%$ and after supplementation the average levels of MDA, GSH, Catalase, SOD and DPPH were found to be, $11.33 \pm 2 \mathrm{nmol} / \mathrm{ml}, 11.85 \pm 2 \mathrm{U} / \mathrm{L}$, $98.35 \pm 36 \mathrm{U} / \mathrm{L}, 82.24 \pm 12 \mathrm{U} / \mathrm{ml}$ and $14.59 \pm 4 \%$ inhibitions respectively. The plasma MDA, GSH, Catalase and DPPH levels were significantly $(\mathrm{P}<0.001)$ changed after supplementation with Eleusine coracana biscuits. No significant change was observed in plasma SOD levels after supplementation with biscuits in Table 8 .

Table 4 Blood glucose levels in GTT (Three days period)

\begin{tabular}{lccccccc}
\hline \multicolumn{7}{l}{ Reference food glucose levels $(\mathbf{m g} / \mathbf{d l})(\mathbf{n}=\mathbf{1 1})$} \\
\hline Time interval & $\mathbf{0}$ min & $\mathbf{1 5} \mathbf{~ m i n}$ & $\mathbf{3 0} \mathbf{~ m i n}$ & $\mathbf{4 5} \mathbf{~ m i n}$ & $\mathbf{6 0} \mathbf{~ m i n}$ & $\mathbf{9 0} \mathbf{~ m i n}$ & $\mathbf{1 2 0} \mathbf{~ m i n}$ \\
\hline Day1 & $98.82 \pm 9$ & $124.81 \pm 15$ & $150.91 \pm 25$ & $144.09 \pm 30$ & $133.73 \pm 39$ & $112.55 \pm 30$ & $93.18 \pm 21$ \\
Day2 & $90.82 \pm 13$ & $122.63 \pm 22$ & $146.27 \pm 38$ & $145.36 \pm 25$ & $144.46 \pm 32$ & $117.2 \pm 31$ & $92.36 \pm 23$ \\
Day3 & $89.19 \pm 16$ & $119.90 \pm 18$ & $148.55 \pm 24$ & $140.54 \pm 23$ & $139 \pm 28$ & $114.95 \pm 29$ & $93.0 \pm 26$ \\
Average & $92.95 \pm 16$ & $122.45 \pm 31$ & $148.58 \pm 39$ & $143.33 \pm 35$ & $139.06 \pm 45$ & $114.92 \pm 33$ & $92.85 \pm 36$ \\
\hline
\end{tabular}


Table 5 Effect of eleusine coracana biscuits on blood glucose level (Three days period)

\begin{tabular}{|c|c|c|c|c|c|c|c|}
\hline \multicolumn{8}{|c|}{ Test food glucose levels(mg/dl) $(n=11)$} \\
\hline Time interval & $0 \mathrm{~min}$ & $15 \mathrm{~min}$ & $30 \mathrm{~min}$ & $45 \mathrm{~min}$ & $60 \mathrm{~min}$ & $90 \mathrm{~min}$ & $120 \mathrm{~min}$ \\
\hline Day1 & $93.4 \pm 10$ & $104.72 \pm 21$ & $112.28 \pm 21$ & $114.18 \pm 12$ & $114.72 \pm 22$ & $107.8 \pm 23$ & $98.64 \pm 18$ \\
\hline Day2 & $89.8 \pm 10$ & $91.09 \pm 6$ & $111.19 \pm 16$ & $107.81 \pm 21$ & $104.1 \pm 25$ & $98.09 \pm 15$ & $94.0 \pm 10$ \\
\hline Day3 & $91.8 \pm 13$ & $102.0 \pm 10$ & $93.03 \pm 14$ & $101.20 \pm 16$ & $107.1 \pm 12$ & $98.09 \pm 19$ & $90.45 \pm 15$ \\
\hline Average & $91.66 \pm 16$ & $99.27 \pm 26$ & $105.49 \pm 28$ & $107.66 \pm 28$ & $108.64 \pm 27$ & $101.50 \pm 28$ & $94.36 \pm 27$ \\
\hline
\end{tabular}

Table 6 Average blood glucose levels of reference food and test food

\begin{tabular}{|c|c|c|c|c|}
\hline $\begin{array}{l}\text { Time interval } \\
(\mathrm{min})\end{array}$ & $\begin{array}{l}\text { Blood glucose levels of } \\
\text { reference food }(\mathrm{mg} / \mathrm{dl})\end{array}$ & $\begin{array}{l}\text { Blood glucose levels of } \\
\text { test food }(\mathrm{mg} / \mathrm{dl})\end{array}$ & $\begin{array}{l}\text { Incremental blood glucose } \\
\text { levels of reference food (mg/ } \\
\text { dl) }\end{array}$ & $\begin{array}{l}\text { Incremental blood glucose } \\
\text { levels of test food }(\mathrm{mg} / \mathrm{dl})\end{array}$ \\
\hline 0 & $92.95 \pm 16$ & $91.66 \pm 16$ & 0 & 0 \\
\hline 15 & $120.45 \pm 31$ & $99.27 \pm 26$ & 27.82 & 6.9 \\
\hline 30 & $148.58 \pm 39$ & $105.49 \pm 28$ & 55.64 & 13.83 \\
\hline 45 & $143.33 \pm 36$ & $107.66 \pm 28$ & 50.875 & 15.4 \\
\hline 60 & $139.06 \pm 45$ & $108.64 \pm 27$ & 46.12 & 16.98 \\
\hline 90 & $114.92 \pm 33$ & $101.50 \pm 28$ & 21.98 & 9.84 \\
\hline 120 & $92.84 \pm 36$ & $94.36 \pm 27$ & -0.1 & 2.7 \\
\hline
\end{tabular}

Table 7 Alterations in lipid and stress profile values after supplementation with Eleusine coracana biscuits in healthy Subjects

\begin{tabular}{lllllll}
\hline \multirow{2}{*}{ S.No } & Lipid profile & \multicolumn{5}{c}{ Stress profile } \\
\cline { 2 - 7 } & Parameter & 1st day & 21st day & Parameter & 1st day & 21st day \\
\hline 1 & HDL(mg/dl) & $57.14 \pm 12$ & $58.47 \pm 12$ & MDA(nmol/ml) & $10.94 \pm 2$ & $11.85 \pm 2$ \\
2 & LDL(mg/dl) & $79.19 \pm 5$ & $77.94 \pm 4$ & GSH (U/L) & $11.80 \pm 2$ & $11.33 \pm 2$ \\
3 & Triglycerides(mg/dl) & $122.96 \pm 16$ & $119.22 \pm 14$ & Catalase (U/L) & $112.95 \pm 45$ & $114.08 \pm 36$ \\
4 & Cholesterol(mg/dl) & $115.97 \pm 32$ & $103.31 \pm 31$ & SOD (U/ml) & $78.76 \pm 11$ & $82.24 \pm 12$ \\
5 & & & & DPPH $(\%$ inhibition $)$ & $112.95 \pm 45$ & $98.35 \pm 36$ \\
\hline
\end{tabular}

Table 8 Stress profile of healthy volunteers before and after supplementation of Eleusine coracana biscuits

\begin{tabular}{llll}
\hline S.No & Parameter & Before supplementation & After supplementation \\
\hline 1 & MDA (nmol/ml) & $11.80 \pm 2$ & $11.33 \pm 2$ \\
2 & GSH (U/L) & $10.94 \pm 2$ & $11.85 \pm 2$ \\
3 & Catalase (U/L) & $112.95 \pm 45$ & $98.35 \pm 36$ \\
4 & SOD (U/ml) & $78.76 \pm 11$ & $82.24 \pm 12$ \\
5 & DPPH(\% of inhibition) & $11.66 \pm 3$ & $14.59 \pm 4$ \\
\hline
\end{tabular}

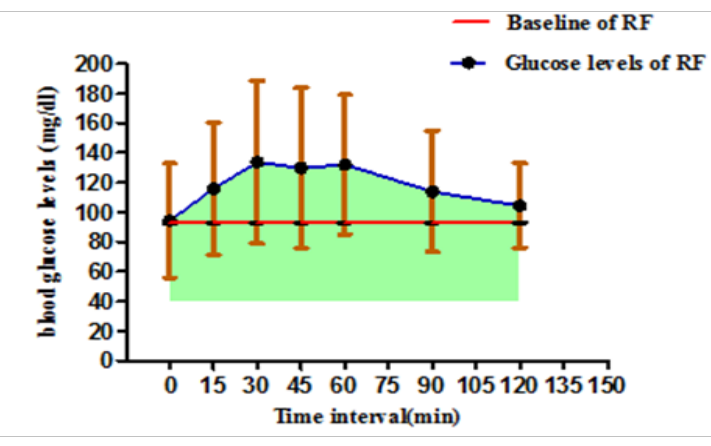

Figure I IAUC of Test food.

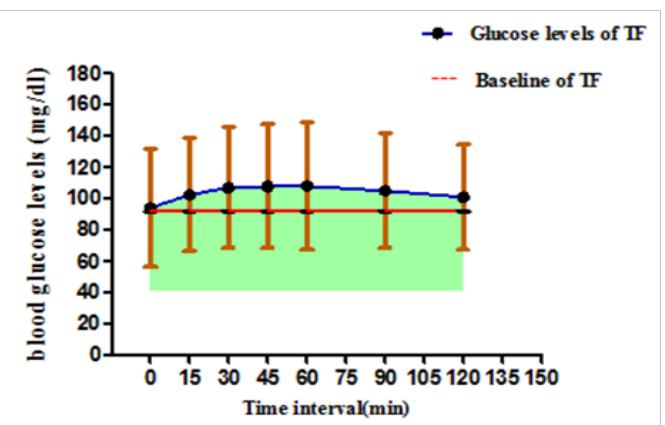

Figure 2 IAUC of Reference food. 


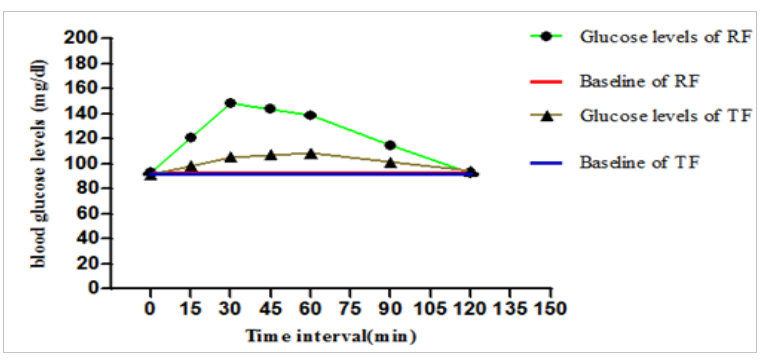

Figure 3 Comparison of IAUC of test and reference food. TF, test food (biscuit); RF, refernce food (glucose).

\section{Discussion}

The primary driver of epidemics of the diabetes is the rapid epidemiological transition associated with changes in dietary patterns. Diet is the basic part of management of diabetes. Treatment cannot be effective unless adequate attention is given to ensuring appropriate nutrition. ${ }^{5,35}$ According to Rome Based bio-diversity international, 7000 species are used as food source out of them 3000 are edible plant species. At present 150 species are cultivated commercially worldwide. In fact only four species- rice, wheat, maize and potato provide $60 \%$ of the human energy. Our food choices are being narrowed down day by day. Among the different categories of the foods millets, roots, tubers and leafy vegetables are most neglected ones. ${ }^{36}$ In case of glycemic index these foods are low compare to rice and hence it is capable of controlling blood sugar levels. ${ }^{37}$

Carbohydrate-rich foods have been classified on the basis of their effects on postprandial glycaemia, as indicated by their GI. The best evidence of the clinical usefulness of GI is available in diabetic patients in whom low-GI foods have consistently shown beneficial effects on blood glucose control in both the short-term and the long-term. Although this type of diet has beneficial effects on lipid metabolism, its high carbohydrate content might hamper its potentially healthful effects in patients with diabetes. ${ }^{38}$

Regular intake of Eleusine coracana which is having low GI (33.95) is known to reduce the risk of diabetes mellitus by low glycemic response and anti-oxidant activity. ${ }^{39}$ Hence it can be consumed by diabetic patients to prevent complications and normal individuals who are susceptible to diabetes. The interest behind formulating a biscuit with Eleusine coracana was to enhance its consumption both by diabetics and non diabetics. Hence in present study we checked its suitability for the diabetic patients by calculating the glycemic index and glycemic load of the prepared biscuit. We found significantly less average blood glucose levels $(91.66 \pm 16 \mathrm{mg} / \mathrm{dl}$ to $108.64 \pm 27 \mathrm{mg} /$ dl) when compared to the reference food $(92.95 \pm 16 \mathrm{mg} / \mathrm{dl}$ to $148.58 \pm 39 \mathrm{mg} / \mathrm{dl}$ ). Accordingly a threefold decrease in incremental blood glucose levels was observed with the prepared biscuits i.e 0 to $16.98 \mathrm{mg} / \mathrm{dl}$ when compared to reference food (0 to $55.64 \mathrm{mg} / \mathrm{dl}$ ). These results clearly demonstrate that the blood glucose levels were moderately increased after feeding with the biscuits prepared with Eleusine corocana.

We calculated the glycemic index of biscuits using IAUC of test food and reference food which was found to be 33.95. By obtained glycemic index value, we have calculated the glycemic load of the test food which was found to be 16.97. According to the global glycemic index scale (0 to 100$)$ glycemic index of 55 or below are considered as low and 70 or above are considered as high and Glycemic load of 10 or below are considered low, and 20 or above are considered high. Hence we can categorize the prepared Eleusine corocana biscuits under low glycemic index and low glycemic load food. The study results clearly demonstrate that the Eleusine corocana biscuits can be consumed by diabetics and non diabetics because of its low glycemic index and load. ${ }^{40}$

Eleusine corocana is also rich of mineral and micronutrients which are quite essential for the body to produce enzymes, hormones and essential substances for proper growth and development. Hence increased consumption of its biscuits may overcome malnutrition thereby strengthen the immune system. ${ }^{41}$

After 21days supplementation with Eleusine coracana biscuits, we have evaluated its effect on stress profile by estimating different antioxidant parameters. The reduced glutathione levels were significantly increased $(p<0.01)$ which may be a reason for the significant improvement $(\mathrm{p}<0.001)$ in total antioxidant status of all the subjects in Table 8. SOD and Catalase ${ }^{42}$ levels were increased but we did not found significant difference for it. Lipid peroxidation end product, ${ }^{43} \mathrm{MDA}$, has significantly $(\mathrm{p}<0.05)$ decreased. This indicates the long-term supplementation with Eleusine coracana biscuits will suppress the stress which is beneficial for both diabetic patients and normal individuals. The reason might be due to the poly phenols content present in the grains. ${ }^{44}$

We have also evaluated the effect of Eleusine coracana biscuits on the lipid profile. We found slight increase in HDL and decrease in LDL, cholesterol, triglycerides. But significant decrease $(\mathrm{p}<0.05)$ was observed only with LDL levels in Table 7. In diabetes and its associated diseases (atherosclerosis) altered lipid profile can be seen hence long-term supplementation with Eleusine coracana biscuits may have beneficial effects particularly by controlling the LDL, cholesterol and triglycerides levels.

\section{Conclusion}

The study indicated that the Eleusine coracana-based biscuits have low GI as well as moderate GL is suitable as a food supplement for both diabetes patients and normal individuals. The GI values of foods were largely dependent on the nature of cereal component. Eleusine coracana based biscuits, on long-term consumption, may yield many other health benefits including control blood LDL levels and improving antioxidant status.

\section{Acknowledgements}

Authors are thankful to the Department of Pharmaceuticals, Ministry of Chemical and Fertilizers, Govt. of India and Indian Institute of Biotechnology, Hyderabad for providing financial assistance to complete the study.

\section{Conflict of interest}

The author declares no conflict of interest.

\section{References}

1. Shobana S, Sreerama Y, Malleshi N. Composition and enzyme inhibitory properties of finger millet (Eleusine coracana L.) seed coat phenolics: Mode of inhibition of $\alpha$-glucosidase and pancreatic amylase. Food Chemistry. 2009;115(4):1268-1273. 
2. American diabetes association. Diagnosis and classification of diabetes mellitus. Diabetes Care. 2003;27(Supply):S5-10.

3. Standl E, Baumgartl H, Fuchtenbusch M, et al. Effect of acarbose on additional insulin therapy in type 2 diabetic patients with late failure of sulphonylurea therapy. Diabetes Obes Metab. 1999;1(4):215-220.

4. Saito N, Sakai H, Suzuki S, et al. Effect of an $\alpha$-glucosidase inhibitor (voglibose), in combination with sulphonylureas, on glycaemic control in type 2 diabetes patients. $J$ Int Med Res. 1998;26(5):219-232.

5. Jenkins DJ, Kendall CW, Augustin LS, et al. Glycemic index: overview of implications in health and disease. Am J ClinNut. 2002;76(1):266S-273.

6. Colombani P. Glycemic index and load-dynamic dietary guidelines in the context of diseases. Physiol Behav. 2004;83(4):603-610.

7. Willett W, Manson J, Liu S. Glycemic index, glycemic load, and risk of type 2 diabetes. Am j Clin Nutr. 2002;76(1):274S-280.

8. Pala V, Sieri S, Masala G, et al. Associations between dietary pattern and lifestyle, anthropometry and other health indicators in the elderly participants of the EPIC-Italy cohort. Nutr Metab Cardiovasc Dis. 2006;16(3):186-201

9. Nordmann AJ, Nordmann A, Briel M, et al. Effects of low carbohydrate vs. Low-fat diets on weight loss and cardiovascular risk factors: A Meta analysis of randomized controlled trials. Arch intern med. 2006;166(3):285-293.

10. Riccardi G, Rivellese AA, Giacco R. Role of glycemic index and glycemic load in the healthy state, in prediabetes, and in diabetes. Am J ClinNutr. 2008;87(1):269-274

11. Wolever TM, Jenkins DJ, Vuksan V, et al. Beneficial effect of lowglycemic index diet in overweight NIDDM subjects. Diabetes Care. 1992;15(4):562-564

12. Stevens J, Ahn K, Juhaeri, et al. Dietary fiber intake and glycemic index and incidence of diabetes in African- American and white adults: the ARIC study. Diabetes Care. 2002;25(10):1715-1721.

13. Barclay AW, Petocz P, McMillan-Price J, et al. Glycemic index, glycemic load, and chronic disease risk-a meta-analysis of observational studies. Am J ClinNutr. 2008;87(3):627-637.

14. Brand-Miller JC, Petocz P, Colagiuri S. Meta-analysis of low-glycemic index diets in the management of diabetes: response to Franz. Diabetes Care. 2003;26(12):3363-3364.

15. Ball SD, Keller KR, Moyer-Mileur LJ, et al. Prolongation of satiety after low versus moderately high glycemic index meals in obese adolescents. Pediatrics. 2003;111(3):488-494.

16. Jenkins DJ, Wolever TM, Taylor RH, et al. Glycemic index of foods: a physiological basis for carbohydrates exchange. Am J Clin Nutr. 1981;34(3):362-366.

17. Chethan S, Sreerama Y, Malleshi N. Mode of inhibition of finger millet malt amylases by the millet phenolics. Food Chemistry. 2008;111(1):187191.

18. Shobana S, Harsha MR, Platel K, et al. Amelioration of hyper glycaemia and its associated complications by finger millet (Eleusine coracana L.) seed coat matter in streptozotocin-induced diabetic rats. $\mathrm{Br} J \mathrm{Nutr}$ 2010;104(12):1787-1795.

19. Lei V, Friis H, Michaelsen K. Spontaneously fermented millet product as a natural probiotic treatment for diarrhoea in young children: an intervention study in Northern Ghana. Int J Food Microbiol. 2006;110(3):246-253.
20. Chandrasekara A, Shahidi F. Determination of antioxidant activity in free and hydrolyzed fractions of millet grains and characterization of their phenolic profiles by HPLC-DAD-ESI-MSn. J Functional Foods. 2011;3(3):144-158.

21. Veenashri BR, Muralikrishna G. In vitro anti-oxidant activity of xylooligosaccharides derived from cereal and millet brans-A comparative study. Food Chemistry. 2011;126(3):1475-1481.

22. Prashant S Hegde, Namakkal S Rajasekaran, Chandra TS. Effects of the antioxidant properties of millet species on oxidative stress and glycemic status in alloxan-induced rats. Nutrition Research. 2005. p. 1109-1120.

23. Hegde PS, Anitha B, Chandra TS. In vivo effect of whole grain flour of fingermillet (Eleusine coracana) and kodo millet (Paspalumscrobiculatum) on rat dermal woundhealing. Indian J Exp Biol. 2005;43(3):254-258.

24. Sripriya G, Chandrasekharan K, Murty VS, et al. ESR spectroscopic studies on free radical quenching action of finger millet (Eleusine coracana). Food Chemistry. 1996;57(4):537-540.

25. Hegde $\mathrm{P}$, Chandrakasan $\mathrm{G}$, Chandra T. Inhibition of collagen glycation and cross linking in vitro by methanolic extracts of Finger millet (Eleusine coracana) and Kodo millet (Paspalum scrobiculatum). The Journal of Nutritional Biochemistry. 2002;13(9):517-521.

26. Chethan S, Dharmesh S, Malleshi N. Inhibition of aldose reductase from cataracted eye lenses by finger millet (Eleusine coracana) polyphenols. Bioorg Med Chem. 2008;16(23):10085-10090.

27. Ohkawa H, Ohishi N, Yagi K. Assay for lipid peroxides in animal tissues by thiobarbituric acid reaction. Anal Biochem. 1979;95(2):351-358.

28. Jenkins DJ, Wolever TM, Taylor RH, et al. Glycemic index of foods: a physiological basis for carbohyderate exchange. Am J ClinNutr. 1981;34(3):362-366.

29. Shobana S, Kumari SR, Malleshi NG, Glycemic response of rice, wheat and finger millet based diabetic food formulations in normoglycemic subjects. Int J Food Sci Nutr. 2007;58(5):363-372.

30. Willett W, Manson J, Liu S. Glycemic index, glycemic load and risk of type 2 diabetis. Am J Clin Nutr. 2002;76(1):274S-280.

31. George L Ellman. Tissue sulfhydryl groups. Arch Biochem Biophys. 1959;82(1):70-77.

32. Aebi H. Catalase-in methods of enzymatic analysis. Bergmeyer HU, editors.USA: Academic press: New York; 1974. p. 673-677.

33. Mishra K, Ojha H, Chaudhury N. Estimation of antiradical properties of antioxidants using DPPH assay: A critical review and results. Food Chemistry. 2012;130(4):1036-1043.

34. Després JP, Lemieux I, Prud'homme D. Treatment of obesity: need to focus on high risk abdominally obese patients. BMJ. 2001;322(7288):716-720

35. Hodge AM, English DR, O Dea K, et al. Glycemic index and dietary fiber and the risk of type 2 diabetes. Diabetes Care. 2004;27(11):2701-2706.

36. Modi M, Modi A, Hendriks S. Potential role for wild vegetables in household food security: A preliminary case study in KwaZulu-Natal, South. Africa. Afr J Food Agric Nutr Dev. 2006;6(1):1-13.

37. Mathanghi SK, K Sudha. Functional and phytochemical properties of finger millet (Eleusinecoracana) for health. IJPCBS. 2012;2(4):431-438.

38. Robertson RP, Harmon J, Tran PO, et al. Glucose toxicity in $\beta$-cells: Type 2 diabetes, good radicals gone bad, and the glutathione connection. Diabetes. 2003;52(3):581-587. 
39. Dibyendu Talukdar. In Vitro Antioxidant Potential and Type II diabetes related enzyme inhibition properties of traditionally processed legumebased food and medicinal recipes in Indian Himalayas. J App Pharm Sci. 2013;3(1):026-032.

40. Atalay M, Laaksonen DE. Diabetes, oxidative stress and physical exercise. J Sports Sci Med. 2002;1(1):1-14.

41. Tovey FI. Diet and duodenal ulcer. J Gastroenterol Hepatol. 1994;9(2):177-185
42. Lortz S. Sequential inactivation of reactive oxygen species by combined overexpression of SOD isoforms and catalase in insulin-producing cells. Free Radic Biol Med. 2003;34(6):683-688.

43. Jain SK, McVie R, Duett J, et al. Erythrocyte membrane lipid peroxidation and glycosylated hemoglobin in diabetes. Diabetes. 1989;38(12):1539 1543.

44. Chethan S, Sreerama YN, Malleshi NG. Mode of inhibition of finger millet malt amylases by the millet phenolics. Food chemistry. 2008;111(1):187191. 